Resenha 



\section{O discurso centrado na harmonia como estratégia política de negociação}

\section{Jessie Jane Vieira de Sousa*}

AMARAL, Deivison. Catolicismo e Trabalho. A cultura militante dos trabalhadores de Belo Horizonte (1909-1941). Curitiba: Editora Prismas, 2018.

Palavras-chave: catolicismo social; movimento operário; Belo Horizonte.

O livro, cuja pesquisa foi originalmente apresentada como tese doutoral no Programa de Pós-Graduação em História Social do Trabalho da Universidade Estadual de Campinas (UNICAMP), se propõe a analisar criticamente o debate historiográfico acerca da construção da identidade operária no Brasil da chamada República Velha e as diferentes formas sobre as quais ela se expressou no processo histórico brasileiro e, em especial, em Belo Horizonte entre os anos de 1909 a 1941.

Através de uma densa pesquisa empírica, o autor nos apresenta os mecanismos pelos quais foi possível a conformação de uma determinada cultura cívica, compreendida como cultura política, no ambiente do catolicismo romanizado então vigente na Igreja Católica no Brasil e, especialmente, na Belo Horizonte de então.

O objeto centra-se na conformação de uma militância especificamente católica articulada através de organizações compostas por trabalhadores, desde a fundação da primeira associação católica leiga, em 1909, até a construção da Confederação Católica do Trabalho (CCT) em 1941. O livro se divide em duas partes. A primeira busca esclarecer o significado do que ele chamou de cultura militante católica e como esta se expressou no associativismo dos trabalhadores na cidade de Belo Horizonte e em outros lugares das Minas Gerais. A segunda parte se dedica a analisar como tal cultura militante se expressou na práxis política e social desses trabalhadores. Seu corpus documental centra-se no semanário O Operário, produzido pela CCT, e nos documentos do poder Legislativo de Belo Horizonte.

A hipótese sobre a qual a pesquisa se articula centra-se na noção de que a militância católica foi forjada na perspectiva política que parte da necessidade e possibilidade da existência de uma harmonia e cooperação entre as classes, como pressuposto da ordem e do progresso. Para o autor, no entanto, essa idealização, incorporada através da doutrina social da Igreja Católica, não significou, necessariamente, que os militantes aderentes a essa estratégia se tornassem

* Doutora em História Social pela Universidade Federal do Rio de Janeiro (UFRJ), instituição da qual foi professora. 
apenas correia de transmissão dos interesses das elites políticas, econômicas ou eclesiásticas. Afirma, ainda, que a defesa de uma sociedade harmônica era para a militância católica uma estratégia de negociação.

Creio que, em linhas gerais, esses seriam os pontos centrais que constituem a elegante narrativa do autor. No entanto, eu gostaria de tecer uns poucos comentários acerca de algumas questões levantadas ao longo do profícuo trabalho.

Inicialmente, parabenizo seu orientador, professor Claudio Batalha, ${ }^{1}$ pelo acolhimento e orientação de uma temática que, como pontuou Deivison, até o final dos anos de 1980, era considerada nos principais programas de pós-graduação como irrelevante diante do que se considerava o protagonismo hegemônico dos anarquistas ou comunistas. Talvez tenha vindo de Luís Werneck Vianna ${ }^{2}$ uma das primeiras pistas sobre a importância da reflexão sobre a presença católica na formulação da legislação trabalhista. Mas, só no final da década é que surgem as novas reflexões acadêmicas a respeito do protagonismo católico no mundo do trabalho ou das classes trabalhadoras em geral. Não se tratava mais de analisar a história da instituição católica ou de suas ações no campo institucional, mas de um olhar crítico sobre o seu envolvimento nas grandes questões próprias de uma sociedade excludente.

E creio que, do ponto de vista teórico-metodológico, a maior contribuição veio de Roberto Romano, ao nos trazer reflexões fundamentais para a compreensão do que ele cunhou como sendo um projeto teológico-político da Igreja Católica. Além do frutífero livro de Alcir Lenharo, ${ }^{3}$ no qual o autor analisa a sacralização das relações entre a Igreja e o Estado varguista exatamente no aspecto ressaltado acima. Especificamente sobre a presença católica no mundo do trabalho, ressalto a pesquisa de Astor Antônio Diehl ${ }^{4}$ que, pela primeira vez, nos apresentou o ativismo circulista. Cito apenas esses autores, que me parecem mais emblemáticos pelo pioneirismo.

A partir dos anos de 1990, outras pesquisas foram realizadas e creio que hoje já podemos contar com uma quantidade razoável de trabalhos que têm o ativismo católico como foco. Contudo, muitos desses trabalhos ainda partem de certa visão apologética, particularmente aquelas centradas na trajetória dos chamados bispos progressistas (nomenclatura cunhada pelos chamados brasilianistas). De qualquer forma, a temática entrou definitivamente no radar dos pesquisadores e já transborda para outros universos religiosos.

A pesquisa de Deivison se insere nessa temática, incorporando novas perspectivas trazidas pela leitura thompsiana e outros autores que, embora dialoguem com o conceito de classe, o fazem a partir de novos paradigmas. Como é o caso do próprio Thompson ao destacar o papel do metodismo, como uma "comunidade de substituição", no processo de criação da solidariedade na constituição da classe operária inglesa.

Creio, como Deivison, que a religião entrou definitivamente na agenda da história social, se entendida como dimensão básica da sociedade industrial e, na

1 Na ocasião, um jovem professor que, juntamente com o meu querido orientador Michael Hall e o inesquecível Marco Aurélio Garcia, foi um dos fundadores do pioneiro programa de História Social do Trabalho, na UNICAMP, programa ao qual eu, como mestranda, tive a honra de ingressar.

2 VIANNA, Luiz Werneck. Liberalismo e sindicato no Brasil. Belo Horizonte: Editora da UFMG, 2000 (reedição).

3 LENHARO, Alcir. A sacralização da política. São Paulo: Papirus, 1986.

4 DIEHL, Astor. Círculos Operários no Rio Grande do Sul: um projeto social-político (dos anos 1930 a 1964). Porto Alegre: Edipucrs, 1990. 
contemporaneidade, por aquilo que muitos estudiosos chamam de a volta do encantamento do mundo. No caso do Brasil, esse fenômeno deverá ser um dos pontos fulcrais para o entendimento da possibilidade da interdição democrática. Talvez um revés da agenda presente na pauta do catolicismo social apresentada ao longo das páginas deste livro.

Outra questão importante é a proposição do autor de analisar o pertencimento subjetivo dos católicos nas associações formadas a partir do universo religioso do catolicismo tridentino. Para Foucault,, 5 nas sociedades circulam classes diferentes de discursos. De um lado, aqueles que são pronunciados e que imediatamente desaparecem. E, de outro, aqueles que se renovam e que são indefinidamente repetidos, ainda que com outras palavras. Neste segundo grupo se encontram os discursos religiosos que se agrupam aos discursos científicos, poéticos, políticos, morais etc. E se constituem em uma determinada leitura da realidade.

Paul Ricoeur ${ }^{6}$ afirma que esse campo discursivo assume três dimensões que, por sua vez, compõem a linguagem religiosa. Para ele, toda fé religiosa constitui uma modalidade particular de discurso que é "sensato" e possui um "sentido" para uma determinada comunidade de crentes. E, nessa perspectiva, torna-se um discurso que tem valor de "verdade". Uma verdade anunciada por uma autoridade eclesiástica e enunciada por encíclicas, pronunciamentos, decretos, homilias etc.

Nessa dimensão, o percurso traçado por Deivison para afirmar a existência de uma militância católica forjada a partir de uma determinada cultura política me parece de grande acuidade. E ele o faz percorrendo novos âmbitos da vivência operária ocorrida nos espaços religiosos mergulhados na chamada doutrina social que, desde o final do século XX, passou a moldar uma nova forma de enfrentamento aos males do capitalismo, tido como fruto do liberalismo. O programa buscou uma terceira via. Nem capitalismo, nem comunismo, com sólidas bases no conservadorismo contrarrevolucionário.

Tradicionalmente, a historiografia se debruçou sobre essa vivência a partir dos espaços de sociabilidades tradicionais da cultura socialista, isto é, os sindicatos e os partidos. A historiografia sobre o anarquismo foi a que mais se preocupou com os espaços de sociabilidade fora dos sindicatos ou partidos mas, por outro lado, centrava-se nos espaços forjados a partir dos projetos educacionais ou culturais construídos através das organizações anarquistas.

No caso em tela, o foco da análise se expande porque busca compreender como o discurso religioso, produzido pelas autoridades eclesiásticas, foi recebido no cotidiano operário. Mais especificamente, como a Rerum Novarum e demais encíclicas foram traduzidas, massificadas e incorporadas como verdades no universo daqueles homens e mulheres que vivenciavam a exclusão social, política, econômica e cultural em um determinado tempo e espaço. E toda essa operação política e cultural realizada por uma instituição que buscava se recolocar no espaço público como consciência moral da sociedade.?

Uma última observação trata da afirmação do autor sobre uma possível independência das organizações católicas até os anos de 1930. Segundo ele, será somente após a fundação da Ação Católica Brasileira, em 1932, que a hierarquia passa a tutelar as organizações operárias. Claro que a transformação da CCT em 
Círculos Operários, como organização oficial, pode nos induzir a tal conclusão. Mas o próprio autor, ao descrever a estrutura hierárquica presente na CCT, aponta a existência do assistente eclesiástico, isto é, um padre. Exatamente o mesmo modelo dos Círculos Operários.

Nas minhas pesquisas e vivências não encontrei nenhuma organização católica que não fosse tutelada, de forma direta ou indireta, pela hierarquia. Afinal, trata-se de uma Igreja hierarquizada e fortemente centralizada. E não seria nos anos vinte e trinta, momentos de romanização e, portanto, de forte centralização, que a hierarquia deixaria que a militância católica, seu exército, estivesse sem tutela. Até mesmo na vigência da Teologia da Libertação essa tutela esteve presente, através da presença do clero ou dos agentes pastorais que eram atores massificadores das orientações eclesiásticas. Essa operação era realizada através da extensa literatura produzida no âmbito da Conferência Nacional dos Bispos que era traduzida nos diferentes materiais impressos, sonoros ou audiovisuais que, por sua vez, eram objeto de leitura e interpretação em cada núcleo. E assim continua sendo na Igreja Católica hoje, mas agora sob outra perspectiva advinda do papado de João Paulo II.

Creio que a grande novidade ocorrida após a fundação da Ação Católica Brasileira foi a renúncia à criação dos sindicatos católicos e a proposta de formação de uma militância católica que disputasse as pautas políticas, com os adversários tradicionais, de dentro dos sindicatos. Claro que estamos falando de uma nova conjuntura surgida após a revolução de 1930, com o Estado buscando protagonismo no mundo do trabalho. Mas, de qualquer forma, não me parece pertinente a ênfase em uma possível independência das associações operárias diante da hierarquia que é, ao fim e ao cabo, ator de primeira grandeza na produção e massificação dos valores que constituem a cultura católica sobre o mundo do trabalho e as estratégias de suas associações.

Compartilho com Deivison a conclusão de que a intervenção da Igreja Católica no mundo do trabalho, através das suas diferentes organizações, contribuiu para o alargamento dos direitos dos trabalhadores, ainda que seu projeto tenha sido sempre de uma modernização conservadora.

Por fim, ressalto a importância da pesquisa apresentada neste livro que, inserida na tradição teórico-metodológica que tem marcado os trabalhos produzidos no âmbito do Programa de Pós-Graduação em História Social do Trabalho da Unicamp, inova ao trazer outros elementos para a compreensão da complexidade da realidade histórica do mundo do trabalho no Brasil. Compreender a complexa relação da cultura religiosa com a política é um desafio fundamental. Particularmente em momentos de fundamentalismos religiosos, como parecem ter sido aqueles pesquisados pelo autor. E, sobretudo, para compreendermos os desafios contemporâneos.

Recebido em 8/11/2018

Aprovado em 3/12/2018 